\title{
'The Last Resort' - the influence of a television programme on referrals to a national unit for affective disorders
}

\author{
A. D. Hodgkiss, Lecturer in Biological Psychiatry, United Medical and Dental \\ Schools of Guy's and St Thomas's Hospitals (University of London) and \\ The Geoffrey Knight National Unit for Affective Disorders, Brook General Hospital, \\ London SE18; A. L. Malizia, Senior Registrar in Psychiatry, St Thomas's Hospital, \\ London SE1; and P. K. BRIDGES, Consultant Psychiatrist and Senior Lecturer, \\ UMDS and The Geoffrey Knight National Unit for Affective Disorders, \\ Brook General Hospital, London SE18
}

On 28 March 1990 a BBC television programme in the 'QED' series was broadcast entitled 'The Last Resort'. It sympathetically showed the life of a woman with a treatment resistant affective disorder and later presented some aspects of her treatment at this unit, including a stereotactic subcaudate tractotomy (SST) operation. As a result of this programme a number of patients wrote to us and this report compares referrals arising in this way with a sample of referrals to the unit through the usual channels.

\section{The study}

All letters and case-notes of people who made contact with the unit as a result of the broadcast were tagged then analysed using a pro forma. Data from the 40 "TV referrals" we assessed were compared with data from a sample of 100 "usual" referrals seen at the unit during the period 1988-1989.

Where statistics are reported, the statistic is $\chi^{2}$ with Yates correction (X). Percentages are reported in brackets where the denominator is readily attributable.

\section{Findings}

Ninety-six letters were received as a result of the programme. Of these letters, 12 were brief requests for written information about the operation. We sent information sheets. The remaining 84 described a psychiatric disorder in the correspondent $(n=34)$ or a close friend or relative $(n=50)$. We replied with either a standard letter explaining that a formal referral from the patient's own doctor, ideally his or her consultant psychiatrist, was needed before we could offer an appointment or, where the diagnosis was clearly not appropriate to the work of this unit, a personal explanatory letter.
Comparison of the 40 TV referrals we eventually assessed with 100 usual referrals to the unit revealed some interesting findings. The two groups contained similar proportions of patients whom we diagnosed as suffering from affective disorders $\mathbf{( 7 8 \%}$ of $\mathrm{TV}$ referrals, $79 \%$ of usual referrals).

The affective disorder samples in the two groups displayed different, but statistically non-significant, female to male ratios $(T V=2.4: 1$, Usual $=6.2: 1$ ) and similar unipolar to bipolar ratios ( $T V=2.4: 1$, Usual 1.6:1). The mean age (TV $=49$ years, Usual $=50$ years) and mean duration of the illnesses (TV $=23$ years, Usual $=17$ years) were similar. Fifty-two per cent of TV referrals and $30 \%$ of usual referrals reported a definite family history of affective disorder.

Comparison of the treatment histories of affective disorder patients in the two groups revealed that $90 \%$ of patients in both groups had been prescribed a tricyclic antidepressant. However, $58 \%$ of our usual referrals had been prescribed tricyclics at doses above $150 \mathrm{mg}$ per day, while only $39 \%$ of TV referrals had been offered these higher doses. Ninetyfour per cent of usual referrals had had ECT compared with $83 \%$ of TV referrals. When treatment with MAOIs, lithium carbonate, L-tryptophan and carbamazepine was considered significant differences were found between the two groups as summarised in Table I.

\section{Comment}

The TV referrals were remarkably similar to our usual referrals in terms of diagnosis, age, duration of disorder and family history. The characteristic of this group was their apparent detachment from local psychiatric services. Only one third were referred by consultant psychiatrists compared with $96 \%$ of our usual referrals. On closer questioning it was confirmed that seven of the $31 \mathrm{TV}$ referrals with affective 
TABLE I

Differences between $T V$ referrals and usual referrals

\begin{tabular}{lccc}
\hline & TV referrals & Usual referrals & Statistics \\
\hline Number assessed & $\mathrm{n}=40(100 \%)$ & $\mathrm{n}=100(100 \%)$ & \\
Referred by psychiatrist & $14(35 \%)$ & $96(96 \%)$ & $\chi^{2}=21.8$ \\
Total of affective disorders & $31(78 \%)$ & $79(79 \%)$ & $P<0.001$ \\
Affective disorder samples & $\mathrm{n}=31(100 \%)$ & $\mathrm{n}=79(100 \%)$ & \\
Men & $9(29 \%)$ & $11(14 \%)$ & \\
Women & $22(71 \%)$ & $68(86 \%)$ & $\chi^{2}=2.5 \mathrm{~N} . \mathrm{S}$ \\
Unipolar & $22(71 \%)$ & $49(62 \%)$ & \\
Bipolar & $9(29 \%)$ & $30(38 \%)$ & $\chi^{2}=0.4$ N.S. \\
Treatment histories & $13(42 \%)$ & $55(70 \%)$ & $\begin{array}{l}\chi^{2}=6.1 \\
P<0.02\end{array}$ \\
Ever had an MAOI? & $8(26 \%)$ & $69(87 \%)$ & $\begin{array}{l}\chi^{2}=9.8 \\
P<0.01\end{array}$ \\
Ever had lithium? & $10(32 \%)$ & $52(66 \%)$ & $\begin{array}{l}\chi^{2}=8.9 \\
P<0.01\end{array}$ \\
Ever had L-tryptophan? & $8(26 \%)$ & $43(54 \%)$ & $\begin{array}{l}\chi^{2}=6.3 \\
P<0.02\end{array}$ \\
Ever had carbamazepine? & & & $P$ \\
& & &
\end{tabular}

disorders were not seeing a consultant psychiatrist at the time of the broadcast.

In order to clarify the mechanism of this detachment from services, we wrote to the seven general practitioners who had referred these patients to our unit and invited them to comment on how it was that the patient was out of touch with local psychiatric services. Of six replies, four indicated that the patient broke contact. In two cases the consultant psychiatrist delegated follow-up to a community psychiatric nurse or social worker.

The TV referrals had received less of all pharmacological and physical treatments for affective disorder than our usual referrals. This under-treatment may be secondary to their relative detachment from local psychiatric services.

\section{Conclusion}

This study suggests that a number of patients with chronic affective disorders become detached from catchment area psychiatric services and consequently remain under-treated. A television broadcast provided a route back to treatment for some of these patients. 